\title{
Region of Creatifity Industries for Disabilities (Balinese Cultural Perspective)
}

\author{
Pande Wayan Renawati ${ }^{1}$ \\ \{panderena@gmail.com ${ }^{1}$ \} \\ Brahma Widya Masters Program, Graduate Program, \\ Denpasar State Hindu Dharma Institute / IHDN Denpasar ${ }^{1}$
}

\begin{abstract}
Bali as an area rich in cultural arts that have long been introduced by ancestors to their successors. As an area of tourism to be a visit of foreign tourists, it has become the world spotlight to always show the development of all natural potential through its innovation. Regarding the development of land for tourism in Bali, it is important to pay attention to people with disabilities to develop disability tourism. For this reason, vacant land is needed for the development of creativity such as sports, cooking / culinary arts, accurate art of ejection / lontar / leaf of rontal writing with Balinese script, the art of sharpening and making tools or sharp objects, singing, developing agriculture, fisheries, plantations, livestock and forestry. In addition, it is also necessary to develop spirituality through yoga, meditation and making canang / from coconut leaf make for offerings with many kinds flowers and incense, as well as the utilization of dried natural products. For this reason, the necessary things are prepared, such as houses, supporting facilities (electricity, water, wifi), vehicles, places of prayer in accordance with their religion, including a special place for the realization of creativity and spirituality.
\end{abstract}

Keywords: Industrial Estate, Creative and Disability.

\section{Introduction}

Bali as a tourist destination has the potential that is very important to realize progress in the future in terms of regional development. The development of the Bali region has always prioritized various aspects of life in terms of economic, industrial, cultural, scientific, social and other aspects. This is done through mature communication by using diverse languages from each country in future cooperation in all aspects. In this case the emphasis is on developing social aspects.

As is known, people's lives are very complex. Primarily in this technology period as a medium for communication is already available in full which makes it easy for businesses to cooperate with various parties. Facing all the bustle both in the office where he works, as well as at home, most of them have forgotten with people who have special needs, their lives are full of suffering who want to develop like normal people in general. Basically, people who are disabled both blind, deaf, mentally disabled, have great potential and need special attention from people who are ready to make it progress and develop and obtain a comfortable and prosperous life in accordance with their abilities, through the tourism industry it is hoped that attracted the attention of visiting tourists, which eventually became a potential tourist disability. This disability tourism is not only a tourist visit, but also an industrial area that can bring profit. To achieve this, the people with disabilities not only live in that place, but are 
empowered according to their abilities. In handling this matter, the attention of the main parties of the government is needed in its development, so that it is not easily taken over by certain parties with special interests. For this reason, a large area of land is needed +1 hectare. There are several issues that require further discussion, namely. 1) What is meant by a creative industrial area for people with disabilities? 2) How will the type of creative industrial area for persons with disabilities be realized? This is discussed as follows through methodological guidelines.

\section{Methodology}

The methodology used is related to the development of the area, education, economy, culture and education and training and assistance needed also in the fields of agriculture, plantations, fisheries and livestock. In connection with this, it is explained as follows.

2.1 Regional development is the main thing that must be pioneered first. This is to determine the extent to which the disability is comfortable in carrying out all activities in accordance with the program to be implemented. According to Joesoef quoted by Nugroho, [1] it is stated that development is a process and involves changes, including renewal in various fields of life ... Development that can meet the needs of the community is development that is fully meaning change must occur within the scope of integral change and not only limited to some aspects of life. It covers the socio-cultural aspects and covers technical, economic, political and other aspects. So the meaning of pioneering regional development must consider the feasibility of the area in accordance with the plan to meet the needs of the disabled. So as to get the desire according to mutual expectations. The disables are happy to carry out activities, and as implementers also achieved socio-cultural balance in the region.

2.2 Education is crucial for the continuity of the disabled. According to Nugroho, [1], it was stated that in accordance with Article 1 of Law No. 20/2003 concerning the National Education System, as follows: "Education is a conscious and planned effort to create a learning atmosphere and learning process so that students actively develop their potential to have religious spiritual strength, self-control, personality, intelligence, noble character, and skills needed by themselves, society, nation and country.

In line with that, the disability is expected to be able to actively develop all the potential that exists in him with existing limitations based on the religious spiritual power he believes in, so that he will be more capable and intelligent in responding to technological developments in the world in the future. come.

To realize this behaviorism is also understood by the students. According to Muijs [2] related to behaviorism it is stated that, through a behavioral learning theory that emphasizes change in behavior as the main outcome of the learning process. So when disabilities follow the path of education, the behavior of the previous ones will be expected to change. For example, behavior that is hard, tense, insecure, easily offended or sensitive through this method will make it better than before.

2.3 The economy becomes a hope point in the progress of the program for implementing the activities of the disabled. When the program has been implemented according to plan, the hope that will be addressed is to get welfare for all implementing components and the disabled. 
2.4 The culture that becomes an icon must be in accordance with the characteristics of Balinese culture, both its buildings, activities, procedures, ethics, and using language as a whole that reflects Balinese culture.

2.5 Counseling and training are carried out by people who have the potential in their fields to become the peak of creativity for disables to do activities so that if they have been achieved properly, they will certainly become more independent but assistance must continue to be carried out to monitor the sustainability of the area.

\section{Results and Discussion}

The results of research, following by :

3.1 Creative Industrial Zone for Persons with Disabilities.

It is an area to produce products that are capable of disability in accordance with their respective hobbies as well as their physical strength in understanding and being able to do it happily. Because if done by force the results will not be able to meet good criteria. The development of this area has its own characteristics with shapes and sizes with integrated and attractive aesthetics. So that it becomes an attraction for tourists who want to visit this disability tourist area. The area has meaning as an area with a certain area that is cool, safe, calm, and peaceful away from the noise of the city, in an area that has a positive natural aura such as good for concentrating mainly when doing yoga and meditation activities, it is very necessary to provide it a special place to carry out yoga and meditation so that people with disabilities can live it diligently which approaches perfection. In addition, several buildings for weaving rooms, Balinese script writing rooms on palm leaves / palm leaves, cooking or culinary rooms, reading rooms / libraries, incense making rooms, sewing rooms / canang making and banten for prayers, prayascita / special offerings for to be holly for all area or people, and others, are suitable places of worship with their respective religion, a place to sharpen and manufacture sharp tools such as knives, machetes and the like. And the important thing is also a residence for those with disabilities. Besides that, for the natural beauty that surrounds it, locations for agriculture, animal husbandry, plantations and fisheries are also prepared. To empower persons with disabilities it is necessary to provide space for exercise of a predetermined size. This dishable sports area consists of several buildings each for basketball, swimming, volleyball, badminton, chess, table tennis, and several other types of sports that make disables healthy until longevity. Of all these activities a space for marketing product results is also needed. Whether it's woven, culinary results that can be used directly as a restaurant to present culinary results for lunch.

3.2 Types of Creative Industries for Persons with Disabilities.

Persons with disabilities need special attention to the government. Although some have been treated, there are still many who experience indifference from their families and the general public. The desire for hope is quite high, generally wanting to enjoy life that is felt by normal people in general. Because of the limited capabilities available, the steps are very limited. But behind human weakness, of course there is hidden power. As people who are given normal strengths, they need to explore the potential of those with disabilities. And not staying silent just feeling sorry for meeting or seeing it. But as a religious leader it certainly has a sense of doing more so that the disables can live happily and happily. The types of Creative Industries for persons with disabilities which should be explored in their potential according to Balinese hobbies and culture are of two types, namely in the form of 
empowering mentality and increasing spirituality. To be understood more broadly, it is presented as follows.

1) To empower mentality, disables are invited to conduct activities such as:

a. Weave.

Weaving according to wikipedia [3] Weaving is explained as the process of making woven goods (cloth) from crossing two sets of thread by entering the feed thread transversely on warp threads (warp threads). Before weaving it was carried out, which was to install warp threads parallel to each other in a loom according to the width of the desired fabric. The loom is used to hold strands of warp threads while the weft thread is inserted transversely between the strands of warp threads and weft threads called webbing. Most of the weaving products are made using three woven techniques: plain woven, satin webbing, and silk woven. Plain fabric is obtained from the results of woven one-color yarn, woven using colorful threads with artistic and decorative designs, to the complicated tapestry. Indonesian traditional weaving crafts include lurik, ikat weaving, songket and geringsing. When making bundles, before they are woven into cloth, strands of yarn are tied and dipped in coloring. Weaving is an activity part of Balinese culture because it has been around since the days of our ancestors. This weaving business is carried out by spinning yarn from cotton to become a cloth according to the style of the local area. In Bali, weaving results are in accordance with each district. Because each regency in Bali has different ways, motifs, patterns, types, woven forms, also with different fabric strengths. These disables need to be invited to weave so that their souls are calm. Because basically if weaving must be based on a patient heart. Because if you are impatient and in a hurry or not calm, the woven fabric is not very good. There fore the key lies in the patience of each person. So mental empowerment in the field of weaving is very important to make his mental strength stronger and not inferior in society.

b. Writing Balinese script

According to wikipedia [4], the meaning of the script is mentioned as a visual symbol system printed on paper and other media (stone, wood, cloth, etc.), to reveal expressive elements in a language. Script is also a writing system. The script is etymologically derived from Sanskrit, namely the words "a" "no", while "kshara" is "destroyed." So characters are something that is not destroyed or is eternal. It is said to be something eternal, because of the role of the script in documenting and ignoring a communication event in written form. Starting from the script that is laid on stone until written on lontar leaves and copper plates the gloom and glory of the past can be touched back with literal evidence.

c. The importance of inviting disables to write Balinese scripts, in addition to remembering the work of ancestors in the past, also to preserve the way of writing palm leaves. The disables will pour their ideas and ideas on palm leaves and it is believed that many disabled people have the potential to write this palm leaf. The direction when the disables are able to express the ejection will serve the visitors to make names, make nameplate, make copies / duplicates of Balinese scripts as well so that this expertise can be developed in other forms of business.

d. Reading in the Library

The disables are able to provide some literature to read so that they have more knowledge that can be applied in the form of activities or help their friends in explaining the meaning related to Balinese cultural knowledge, and other fields which are their skills to be developed further. 
e. Majejahitan or Making Offerings by coconut leaf

According to article in website [5] it is mentioned that. Mejejahitan is a skill in a handwork, using the means of leaves such as coconut, slepan, ron, ambu, lontar, betel leaf, wood leaf, banana leaf and the like. The leaves are cut with a knife and then formed and finally squeezed or arranged using a pin. Mejejahitan basically contains the concept of beauty or aesthetics, very interesting to be seen so that everyone wants to learn, because various forms can be shown. All circumcisions use ornaments with technical overlays and margins so that they contain symbolic or symbolic forms of offerings. Besides that, it also functions as decoration, namely of decoration, which is Balinese Hinduism symbolic, for example tamiang, kolem, hanging-hangers, lamak and others. The need for disables to do this is to show visitors that even if dishable but has the ability and soul of art also to work and prepare ceremonies like other normal people and of course also participate as a successor in preserving Balinese culture.

f. Making Balinese specialties.

According to wikipedia [6], Indonesian cuisine is one of the richest culinary traditions in the world and full of strong tastes. The richness of this type of cuisine is a reflection of the diversity of cultures and traditions of the archipelago which consists of 6000 inhabited islands and occupies an important role in Indonesian national culture in general. Water all Indonesian dishes are rich in herbs derived from spices such as candlenut, chili, temu kunci, galangale, ginger , kencur, coconut turmeric, and palm sugar followed by the use of cooking techniques according to traditional ingredients and traditions, there were also influences from trade originating from India, China, the Middle East and Europe. In connection with this, cooking is one of the activities highlighted by the disables. It is believed that the disables like to cook according to the procedures and types of cuisine from the local area. Therefore it is necessary to be trained in cooking for various types of Balinese cuisine including the types of cakes that can be made and often used during ceremonies.

g. Producing Incense

The disables are directed to be empowered through counseling to develop their abilities in producing incense. As according to https://id.m.wikihow.com/MembuatDupa mentioned that incense is used in various cultures for various purposes such as part of religious ceremonies or aromatherapy. The process of making incense is quite simple and can provide satisfaction for those who are interested in making incense with their own choice of aroma. With the ability of the disabled to make incense, when visitors who come will be able to display the work to be used as a prayer tool and aroma therapy in the spaces that visitors like to place.

h. Plantation Management

Activities for managing plantations can be carried out by the disables according to their hobbies. The types of plantations that can be used as commodities are corn, eggplant, fruits such as mangoes, bananas, durians, and many more including coffee, cloves, and all that will be delivered by the extension agents before the activity is carried out. 
i. Livestock Management

Activities for managing farms can also be carried out by disables such as pigs, goats, cows, chickens (there are broiler chickens, native chickens, chickens for upakara / offerings), and ducks.

j. Fisheries Management

If the place is adequate, a pond can be created to manage fisheries such as tilapia, catfish, carp and the like. Diabel people can be trained so that in the future they can produce fish that can be sold or served in restaurants around the area.

k. Sports development

Sports certainly do not miss the people with disabilities. For sports activities a place can be provided for him to carry out sports activities with assistance, so that in the future he can participate in tournaments both at the regional and provincial levels such as following the ASEAN Para Games.

1. Product marketing

The marketing of products made by disabilities is very much awaited. Because with its limitations, it is not necessarily unable to produce the expected product. This product marketing includes all disable works produced from counseling and mentoring. Both from weaving, sticky lontar, making incense, including culinary that can be served, to the results of plantations, fisheries and livestock. According to https://www.finansialku.com/strategi-pemasaran-produk/ mentioned that. In the business of selling products, marketing techniques and strategies are very influential on the number of sales of products that you will sell. In addition to maintaining the marketing process, you can also keep your customers loyal to your product purchases. The point is that the manager of product marketing must be able to guarantee the certainty that the products produced can be liked and purchased by these visitors.

2) To increase spirituality, the disables are invited to do the following activities:

a. Invite him to pray

As a religious people, of course, always remember God the Creator of the universe. The disables are very ready to be invited to pray. Praying is very important so that the disability feels calm in living life. In connection with this, the author shares experiences related to teaching mute deaf / kolok in Bengkala Village, Kubutambahan District, Buleleng Regency. Residents of kolok are eager to learn to pray because they have never been taught for this. So when taught by kolok residents, they were very concerned about seeing the motion of the code that the writer taught and exhibited by the father of a ruler of Sign Language / Kata Kolok / Mekata greetings of people in the region. Here are some photos of the activities of writers who have also been taught massage, yoga, yoga dancing, whose name is Yogi Nandini, the dance of the prime. 


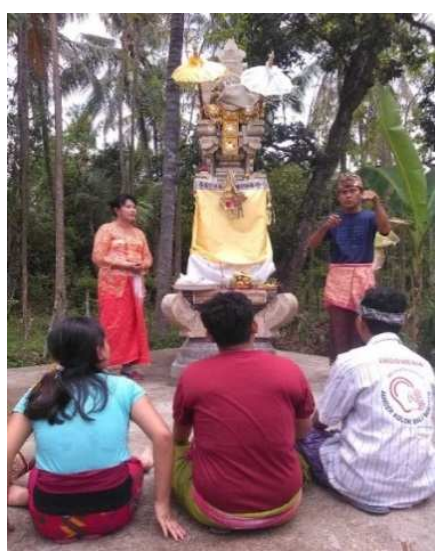

Fig. 1. Teach Dishable for offerings

b. Invite him to carry out yoga

Yoga is very important for life. Yoga was introduced by Maharsi Patanjali from India. Then it developed in Indonesia until now in Bali. The yoga movement was felt very calm and reconciled the atmosphere. This is very important for people with disabilities especially in reassuring their souls. Just like when the writer teaches yoga in Buleleng. Mute deaf residents look very insecure when approached, sensitive, easily offended, but after yoga continues to be trained on him, now it has begun to change. The ones who had been hostile had begun to want to get close to each other and get close again. Herein lies the author's satisfaction in developing yoga specifically created for the disabled and the elderly, so that it feels fit to look at the faces of the disabled. The meaning of yoga according to article in website [7] mentioned that.

1) capitalized: a Hindu theistic philosophy of teaching suppression of all activity of the body, mind, and will in order that the self may realize its distinction from them and attain liberation.

2) a system of physical postures, breathing techniques, and sometimes to promote physical and emotional well-being.

It is interpreted by the Capitalization of a Hindu theistic philosophy that teaches about the emphasis on all activities of the body, mind, and will so that the self can realize the difference from it and achieve liberation. Furthermore, it is intended that the system of physical posture, breathing techniques and sometimes meditation comes from yoga but is often practiced independently especially in western cultures to improve physical and emotional well-being. 


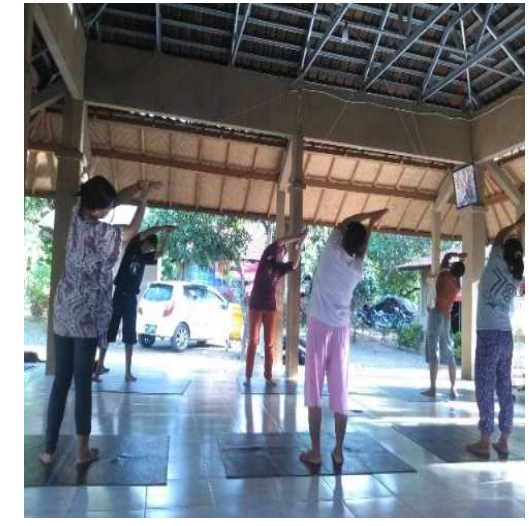

Fig. 2. Teach Yoga

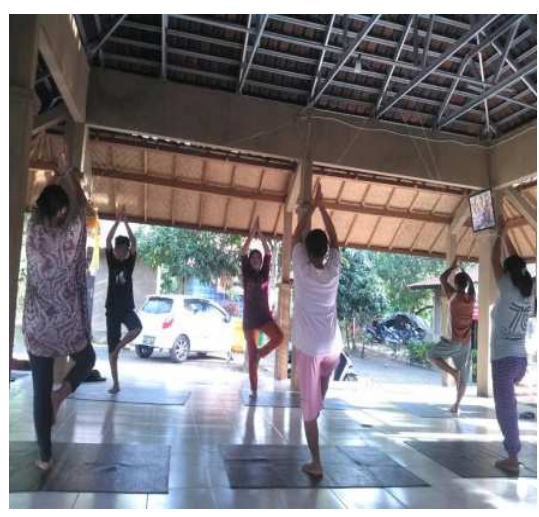

Fig. 3. Teach of yoga

In connection with the foregoing, yoga for persons with disabilities taught in Bengkala Village, Kubutambahan Sub-District, Buleleng Regency, as a feeling of wanting to make persons with disabilities abandon irritable, high emotions, syncritic souls, and bad thinking.

c. Invite him to practice meditation

Meditation really needs to be introduced and trained more for people with disabilities. That made him calmer than before, and made his life happier. This is because meditation is done by releasing all the tension of the mind, returning to the purity of the soul that leads to the direction of perfection and of course concentration of mind which is focused on the greatness of God's power as the creator of the universe with all its contents. And it must be in the awareness and confidence of the origin of everything that exists.

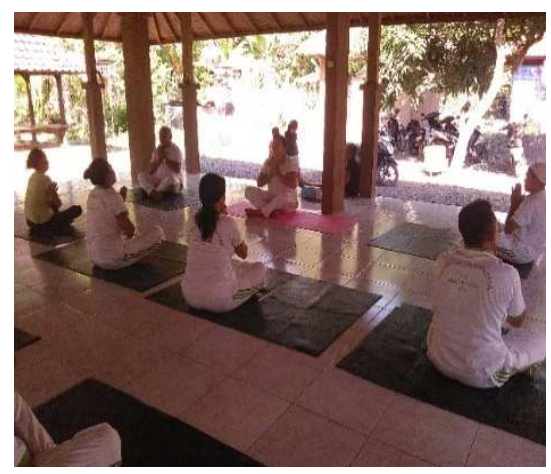

Fig. 4. Meditation

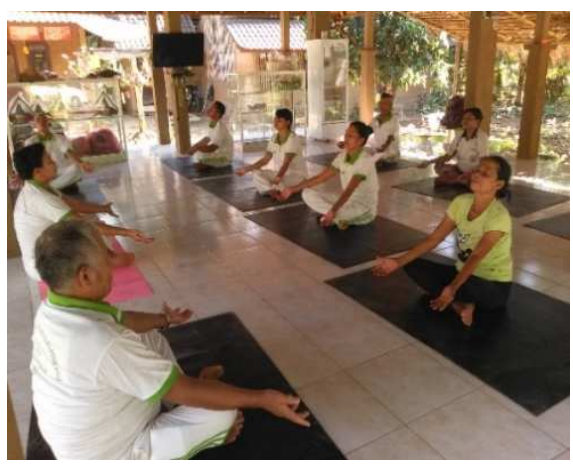

Fig. 5. Meditation 
d. Invite him to practice massage

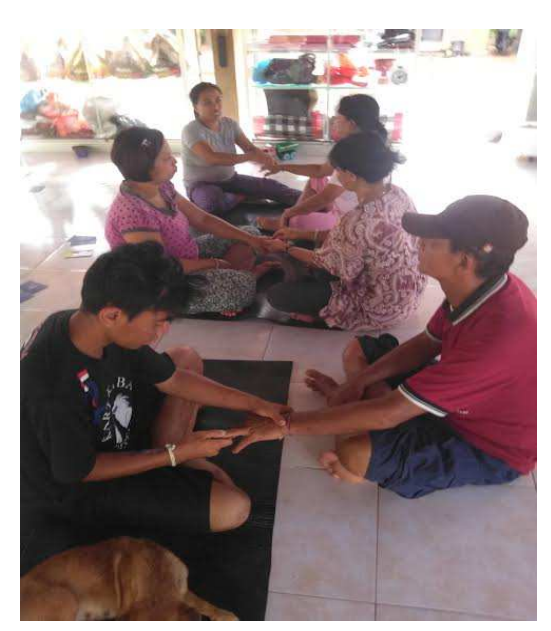

Fig. 6. Teach Massage

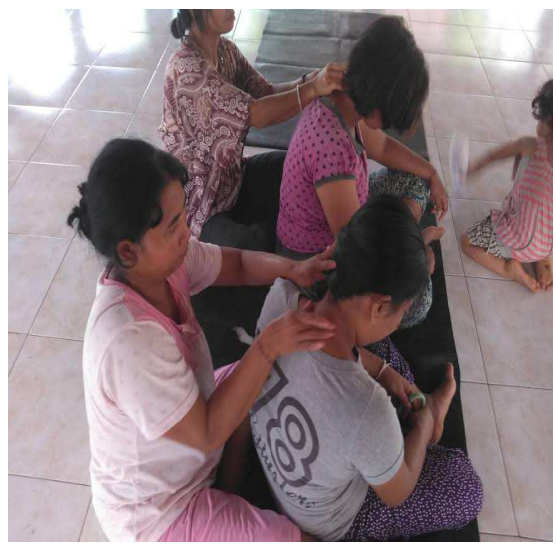

Fig.7. Teaching massage to mute deaf residents

Inviting him to practice massage or massage will not only make the veins become weaker and saggy which will launch blood, it will also make people with disabilities more cheerful and full of joyful life. So that all the stresses and pressures they experience both at home and in their environment will diminish and feel lighter. Thus making his life more meaningful, valued and respected like normal people in general.

e. Inviting Yogi Nandini Dancing Training

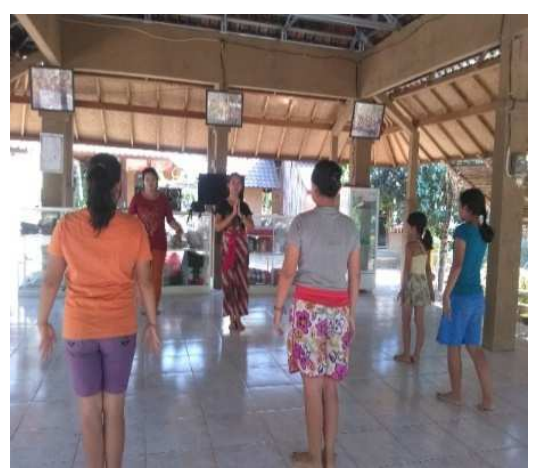

Fig. 8. Teaching dancing

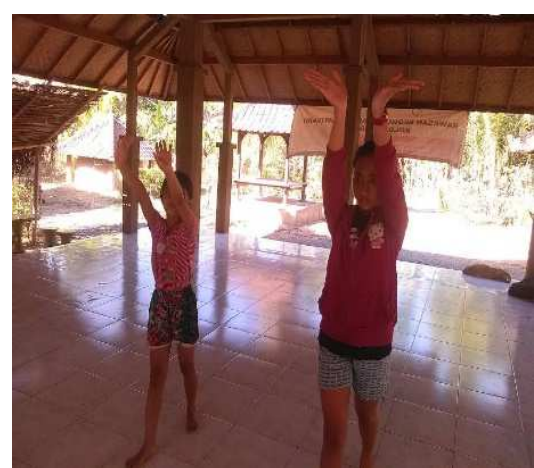

Fig. 9. Teaching Dancing

Invites to take part in the Yogi Nandini Dance training which is an inaugural dance created and inspired by the practice of yoga, which illustrates the pleasant happiness of yogis. Because the word "yogi" is interpreted as the success of a person doing yoga with full appreciation containing self-purification before focusing on yoga and practicing the movement full of high concentration on God. Whereas Nandini means 
fun, or gets happiness. This dance is danced softly and gracefully like a sacred dance danced for apsari or bidadari, a charming and exotic paradise.

f. Invite managers to explore English.

In the present time English is not a new thing, but in the midst of this development, there are still people who don't speak English. It can also be understood that English is not the mother tongue that is used daily by the Indonesian population. Even so, it is very necessary to study well. Therefore, English has also been taught in Bengkala specifically for its managers with a focus on deepening the language so that it can make it easier to communicate with foreigners who come to visit.

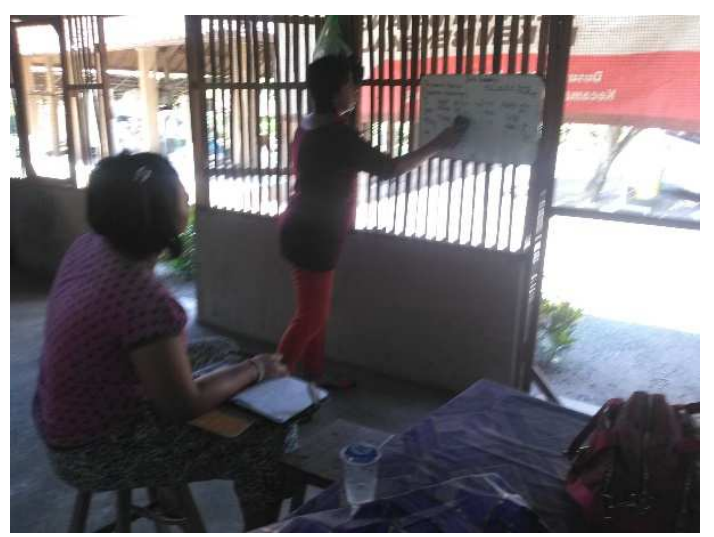

Fig. 10. Teaching English language

\section{Conclusion}

Things that can be drawn as conclusions from this paper are.

4.1 Creative Industrial Zone for Persons with Disabilities. It is an area to produce products that are capable of disability in accordance with their respective hobbies as well as their physical strength in understanding and being able to do it happily. Because if done by force the results will not be able to meet good criteria. The development of this area has its own characteristics with shapes and sizes with integrated and attractive aesthetics. So that it becomes an attraction for tourists who want to visit this disability tourist area.

4.2 The types of creative industries for persons with disabilities which should be explored in their potential according to Balinese hobbies and culture are of two types, namely in the form of empowering mentality and increasing spirituality. Empowerment of mentality is directed at teaching weaving / weaving, writing Balinese script, making knowledge in the library, sewing or making offerings / offerings, making Balinese dishes, producing incense, Managing plantations, animal husbandry, fisheries, developing sports, then marketing production. Furthermore, related to spiritual development, there is a prayer teaching for persons with disabilities, carrying out yoga, doing meditation, teaching massage, teaching yoga dances and the main thing is the manager must speak English. 
Thus the conclusions that have been presented are expected that affection for fellow human beings can be realized by accommodating them in one place with a management management that is especially useful for all persons with disabilities to be able to realize disability tourism with a beautiful and adequate industrial area on the island of Bali and can be used as a model for areas of persons with disabilities in other countries. Astungkara

\section{References}

[1] Nugroho, R.: Excellent Education Policy. Case Educational Development in Jembrana District 2000-2008. Student Library, Yogyakarta (2008)

[2] Muijs, D., \& D. Reynolds.: Effective Teaching theory and Application. Sage Publications Ltd, London (2008)

[3] "https://id.m.wikipedia.org/wiki/ Weave."

[4] "https://id.m.wikipedia.org/wiki/Aksara."

[5] "http://desatamblang.blogspot.com/2."

[6] "https://id.m.wikipedia.org/wiki/Hidangan_Indonesia."

[7] "https://www.merriam-webster.com/dictionary/yoga." 